\title{
Ectonucleotidases and Epilepsy
}

\author{
Giana de Paula Cognato ${ }^{1}$ and Carla Denise Bonan*,2,3
}

\author{
${ }^{I}$ Departamento de Bioquímica, Instituto de Ciências Básicas da Saúde, Universidade Federal do Rio Grande do Sul, \\ Avenida Ramiro Barcelos, 2600- ANEXO, Porto Alegre, RS, Brasil \\ ${ }^{2}$ Laboratório de Neuroquímica e Psicofarmacologia, Departamento de Biologia Celular e Molecular, Faculdade de \\ Biociências, Pontifícia Universidade Católica do Rio Grande do Sul. Avenida Ipiranga, 6681 - Prédio 12, Bloco D, $3^{\circ}$. \\ andar, 90619-900, Porto Alegre, RS, Brasil \\ ${ }^{3}$ Instituto Nacional de Ciência e Tecnologia Translacional em Medicina (INCT-TM), 90035-003, Porto Alegre, RS \\ Brazil
}

\begin{abstract}
Adenosine has been proposed as an endogenous anticonvulsant which can play an important role in seizure initiation, propagation and arrest. Extracellular ATP and adenosine are able to modulate synaptic activity through activation of $\mathrm{P} 2$ ( $\mathrm{P} 2 \mathrm{X}$ and $\mathrm{P} 2 \mathrm{Y})$ and $\mathrm{P} 1$ receptors $\left(\mathrm{A}_{1}, \mathrm{~A}_{2 \mathrm{~A}}, \mathrm{~A}_{2 \mathrm{~B}}\right.$, and $\left.\mathrm{A}_{3}\right)$, respectively. Besides the release of adenosine per se, the levels of ATP and adenosine in the synaptic cleft are controlled by a complex cascade of cell surface-localized enzymes collectively known as ectonucleotidases. These enzymes are capable of hydrolyzing nucleoside triphosphates, diphosphates and monophosphates to their respective nucleosides. There are four major families of ectonucleotidases: ectonucleoside triphosphate diphosphohydrolases (E-NTPDases), ecto-nucleotide pyrophosphatase/phosphodiesterases (ENPPs), alkaline phosphatases and ecto-5'-nucleotidase. All these members have specific physiological functions in the brain. In this review, the involvement of ectonucleotidases in the pathophysiology of brain disorders, such as seizures and epilepsy, is discussed. A brief introduction about the general characteristics of these enzymes is followed by a discussion about the role of ectonucleotidases in epilepsy and seizures and the implications for future treatments.
\end{abstract}

Keywords: Adenosine, ectonucleotidases, extracellular ATP, epilepsy, seizures.

\section{INTRODUCTION}

Extracellular nucleotides and nucleosides are ubiquitous signaling molecules found in both the central nervous system (CNS) and the peripheral nervous system (PNS) [1]. Nucleotides are released from cells or by selective transport through the plasma membrane [2], and can also be generated extracellularly by nucleoside diphosphokinases and adenylate kinases [3]. ATP is stored in the synaptic vesicle together with other transmitters and it is released into the synaptic cleft upon exocytosis [4]. Additional release mechanisms for ATP and other nucleotides such as UTP and UDP [5] include release via connexin or pannexin hemichannels, anion channels or constitutive release via the secretory pathway $[2,6]$. Apart from nerves, the main source of ATP during P2 receptor activation was thought to come from damaged or dying cells. However, it is now known that ATP is released from many cell types, including glial cells, in response to mechanical deformation, hypoxia and other agents that do not damage the cell [7].

Extracellular nucleotides exert their effects through two major receptor subfamilies: P2X, which are ligand-gated ion channels comprising a family of seven receptors, and P2Y, a group of eight G-protein coupled receptors [6, 8]. Neurotransmission, considered a short-term effect, is mediated by

*Address correspondence to this author at the Faculdade de Biociências, Pontifícia Universidade Católica do Rio Grande do Sul. Avenida Ipiranga, 6681 - Prédio 12, Bloco D, $3^{\circ}$. andar, 90619-900, Porto Alegre, RS, Brasil; Tel: + 55513353 4158; Fax: + 5551 33203568; E-mail: cbonan@ pucrs.br
P2X receptors that bind mainly ATP, whereas long-term effects, such as cytotoxicity, cell proliferation, differentiation and migration, occur mainly through $\mathrm{P} 2 \mathrm{Y}$ receptors that bind both purine and pyrimidine nucleotides [7, 9].

Considering their importance in cell signaling, the concentration of extracellular nucleotides is tightly regulated by a variety of cell surface-located enzymes named ectonucleotidases. These enzymes are capable of hydrolyzing nucleoside triphosphates, diphosphates and monophosphates to their respective nucleosides $[10,11]$. There are four major families of ectonucleotidases, namely E-NTPDases (ectonucleoside triphosphate diphosphohydrolases), E-NPPs (ectonucleotide pyrophosphate/phosphodiesterases), alkaline phosphatases and ecto-5'-nucleotidase [11, 12, 13]. In several tissues and cells, ectonucleotidases operate jointly with other enzymes such as adenylate kinase, nucleoside diphosphate kinase, ecto-F1-Fo ATP synthases, and CD38/NADase [12] to form a complex cell surface-localized machine for nucleotide hydrolysis.

In addition to their role in the inactivation of purinergic signaling, ectonucleotidases have been proposed to prevent P2 receptor desensitization [14] and control the availability of ligands to nucleotide and adenosine receptors $[15,16]$. Adenosine can be produced by extracellular nucleotide hydrolysis or released through bidirectional nucleoside transporters [17]. Adenosine binds to the G-protein-coupled receptors $\mathrm{A}_{1}, \mathrm{~A}_{2 \mathrm{~A}}, \mathrm{~A}_{2 \mathrm{~B}}$, and $\mathrm{A}_{3}$, of which $\mathrm{A}_{1}$ and $\mathrm{A}_{2 \mathrm{~A}}$ are highly expressed in the brain [18]. Adenosine activation of $\mathrm{G}_{\mathrm{i} / \mathrm{o}^{-}}$ coupled $A_{1}$ receptors depresses neuronal firing, and reduces 
neurotransmitter release at pre-synaptic nerve terminals while it simultaneously increases potassium conductance and reduces calcium flux in pre- and post-synaptic compartments. The excitatory action of adenosine on neurotransmitter release has been demonstrated, most notably through the activation of the $G_{s / \text { olf }}$ coupled $A_{2 A}$ receptor [19]. Several studies have suggested the role of adenosine as an endogenous anticonvulsant [20,21].

These findings suggest that an imbalance of adenosine regulation or deficiencies within the adenosine-based neuromodulatory system may aggravate seizures and contribute to epileptogenesis [22,23]. Therefore, tight control of ATP and adenosine levels through a highly sophisticated pathway of ectonucleotidases may represent an important mechanism in the modulation of seizure activity and epileptogenesis. This review is divided in sections focusing the role of ectonucleotidases and features in central nervous system (Section 1: Ectonucleotidases) and summarizes recent findings about the involvement of these enzymes in epilepsy and seizures (Section 2: Epilepsy, Seizures and Ectonucleotidases).

\section{ECTONUCLEOTIDASES}

Epilepsy and seizures are characterized by episodes of paroxysmal brain dysfunction due to a sudden, disorderly, and excessive neuronal discharge located in specific brain regions. However, there are other systemic and non-neuronal processes that could play a role in this field, such as inflammation, metabolism disorders, and blood-brain barrier dysfunctions. In this section, we describe the main characteristics of ectonucleotidases and their actions in several tissues, highlighting their role in central nervous system.

\subsection{NTPDases}

NTPDases (ecto-nucleoside triphosphate diphosphohydrolases, ATP diphosphohydrolase, CD39) are a group of glycosylated enzymes that hydrolyze extracellular nucleoside tri- and diphosphates to nucleoside monophosphates. Millimolar concentrations of either $\mathrm{Ca}^{2+}$ or $\mathrm{Mg}^{2+}$ can stimulate NTPDase activity, which is very low if these cations are absent. NTPDases have an alkaline $\mathrm{pH}$ optimum and they are not inhibited by blockers of various intracellular ATPases, such as P-, F- and V-type ATPases or alkaline phosphatases $[24,25]$. By design, a NTPDase inhibitor should not be a P2 receptor agonist or antagonist and also should not be dephosphorylated by ecto-enzymes [26]. Possible inhibitors include 8-thiobutyryl-adenosine 5'-triphosphate (8-BuSATP) and 6,N,N-diethy-D- $\beta, \gamma$-dibromomethylene ATP (ARL 67156), an analogue of ATP and 1-naphtol-3,6,disulfonic acid (BG0136) [26,27].

At least eight different members of the NTPDase family (NTPDases 1-8) have been discovered, cloned and studied over the last few years. Each NTPDase member possesses different enzymatic properties and distinct cellular localization. The feature that all NTPDases share is that they contain five highly conserved sequence domains known as "apyrase conserved regions" abbreviated as ACR1 to ACR5 [28]. ACRs play a central role in forming the catalytic site and all NTPDases show a high degree of similarity in their amino acid sequences. Structural analyses have demonstrated that ACRs are found in the large extracellular domain of CD39 and are strongly conserved phylogenetically [28,29]. These enzymes are similarly synthesized as integral membrane proteins, with their active sites located in the lumen of the endoplasmic reticulum (ER), but undergo different modes of trafficking and are routed to the ER and Golgi (NTPDases47), or to the plasma membrane (NTPDases1-3 and 8). NTPDase 5 and 6 can have their $\mathrm{N}$-terminal signal sequences cleaved, resulting in their release as soluble forms to the extracellular space. NTPDase 1-3 and 8 possess similar amino acid sequences and membrane topology with two membrane spanning domains and catalytic sites facing the extracellular milieu $[12,30]$.

There is evidence that the substrate preference among the members of the E-NTPDase family may result from small differences in protein structure [10]. NTPDase1 hydrolyses ATP and ADP equally well (NTP $\approx$ NDP) while NTPDases3 and 8 prefer to hydrolyze ATP over ADP (NTP > NDP). NTPDase 2 has high hydrolyzing activity toward nucleoside triphosphates (NTP $>>>$ NDP) and for this reason it was designated as an ecto-ATPase years ago [10, 31]. NTPDase4 and 5 hydrolyze nucleotides in this order: UDP > GDP > CDP, while NTPDase6 has a preference for the order GDP > IDP > UDP and NTPDase7 hydrolyzes uridine, guanosine and cytosine tri-phosphates (UTP, GTP, CTP) [12]. NTPDases also form homo-oligomeric assemblies [32]. NTPDases1-3 are found as dimers to tetramers and are firmly anchored to the plasma membrane by two terminal transmembrane domains. Theoretical models based on the crystal structure of exopolyphosphatase/guanosine pentaphosphate phosphohydrolase (PPX/GPPA) have confirmed that the extracellular regions of various members of the NTPDase family are quite similar. The common structure consists of two main lobe domains that are joined to form a deep cleft between them. ACRs 1 and 4 are located on either side of this structure and the active pocket of the enzyme is situated inside the cleft [33-35].

NTPDases1, 2, and 3 are expressed in nervous tissue and mediate the termination of ATP signaling in the synaptic cleft [36]. NTPDase1 is localized at the surface of endothelial vessels in the CNS and is strongly expressed in microglia [37]. NTPDase 2 is associated with progenitor cells in the adult rodent brain $[38,39]$ and is expressed in cultured astrocytes [40]. NTPDase3 is highly expressed in the brain [41, 42] and immunohistochemistry studies have revealed that this enzyme is strongly associated with neurons expressing hipocretine1/orexin-A [43]. NTPDase4 is localized to the Golgi (UDPase, NTPDase4 $\beta$ ) and found in lysosomal/autophagic vacuoles (NTPDase4 $\alpha$ ) [44]. NTPDases5 and 6 are involved in the folding process of glycoproteins and they preferentially hydrolyze nucleoside diphosphates [45, 46]. NTPDase7 (LALP1) hydrolyzes nucleoside triphosphates and is located in intracellular vesicles [47]. NTPDase 8 expression is very low in the brain but it is expressed in the liver, kidney, and jejunum [48].

\subsection{E-NPPs}

The E-NPP (ecto-nucleotide pyrophosphatase/phosphodiesterases) members represent a family of ubiquitous and conserved proteins, which can hydrolyze 5'-phosphodiester bonds in nucleotides and their derivatives, resulting in the release of 5'-nucleoside monophosphates [49-51]. Diadenosine polyphosphates $\left(\mathrm{Ap}_{\mathrm{n}} \mathrm{A}\right)$, an E-NPPs substrate, contain 
two adenosine moieties at the 5' position of ribose rings connected by a polyphosphate chain composed of two or more members. They are the most studied members of the large family of dinucleoside polyphosphates, a group of dinucleotides with intriguing biological functions [52].

E-NPP may be considered as the first step of an ectoenzymatic cascade responsible for the catabolism of extracellular dinucleotides that ultimately results in adenosine and other nucleosides that are salvaged by transport systems inside cells [53].

Mammalian genomes contain at least seven distinct NPPencoding genes, but only three NPPs (NPP1-3) show significant $(40-50 \%)$ sequence similarities at the protein level. These members are classified as type II transmembrane glycoproteins characterized by an intracellular N-terminal domain, a single transmembrane domain and a large extracellular domain [51]. Previous studies have demonstrated that this extracellular domain is composed of two somatomedin-Blike homodimerization motifs, a catalytic domain, and a putative C-terminal "EF-hand" motif $[54,55]$.

Current evidence suggests that E-NPPs have multiple physiological roles, including nucleotide recycling, modulation of purinergic receptor signaling, regulation of extracellular pyrophosphate levels, stimulation of cell motility, and possible roles in regulation of insulin receptor (IR) signaling and activity of ecto-kinases [50]. E-NPPs are optimal at highly alkaline $\mathrm{pH}$ values, but they also retain significant catalytic activity at a $\mathrm{pH} 7.4$ [56].

To date, three E-NPP isoforms have been found in the central nervous system. NPP1 is expressed in the capillaries of the brain [57] and in rat C6 glioma cells [58, 59], but it is not detected in neurons or glia [50]. NPP2 and NPP3 are expressed in choroid-plexus epithelial cells [60, 61] and likely contribute to the secretion of CSF [61]. A splice variant of NPP2a has been identified during intermediate stages of rat brain oligodendrocyte differentiation and myelin formation [50]. Moreover, this enzyme can produce lysophosphatidic acid (LPA), an important molecule for cerebral maturation. In the developing brain, NPP3 is expressed in immature astrocytes [62]. At the mRNA level, the expression of NPP2 mRNA was found in the hippocampus, cerebral cortex, olfactory bulb, cerebellum and striatum during development [63]. NPP1 mRNA increases throughout maturation whereas NPP3 has been demonstrated to decrease with age [63]. Recently, Langer and coworkers [64] demonstrated that similar to NTPDase 1, alkaline phosphatase, and ecto-5'nucleotidase, E-NPP activity (also named Thiamine pyrophosphatase; TPPase) is associated with the neuropil, particularly in the caudoputamen, hypothalamus, and the middle cerebral peduncle [64].

\subsection{Alkaline Phosphatases}

Alkaline phosphatases (APs) are non-specific phosphomonoesterases present in many organisms. Most alkaline phosphatases are homodimeric enzymes that contain three metal ions (two $\mathrm{Zn}$ and one $\mathrm{Mg}$ ) in the catalytic site, which are required for enzyme activity [65]. While the main features of the catalytic mechanism are conserved between mammalian and bacterial APs, mammalian APs have higher specific activity and $\mathrm{K}_{\mathrm{M}}$ values, are optimal at more alkaline $\mathrm{pH}$ values (however, they can also hydrolyze ATP at pH7.4), display lower heat stability, are membrane-bound and are inhibited by L-amino acids and peptides through an uncompetitive mechanism [65]. They release inorganic phosphate from a variety of organic compounds and degrade nucleosides 5'-tri-, -di- and -monophosphates. Five isoforms of these enzymes have been already identified in the mouse [66]. These enzymes may also produce ligands for P2 receptors and, by sequential dephosphorylation, generate the P1 receptor agonist adenosine.

While the role of bone tissue non-specific alkaline phosphatase (TNAP) during the development and mineralization of the skeleton is well established, the functions of APs in other organs are less understood. TNAP is anchored to the plasma membrane through a glycosylphosphatidylinositol group and is absent from the rodent brain, except for its association with endothelia of brain capillaries [67]. Electronmicroscopy studies have suggested that this enzyme is also associated with astrocyte endfeet at the vascular basement membrane and with immature oligodendrocytes [68,69]. Recently, Langer et al. [64] confirmed that the most prominent catalytic activity of TNAP is associated with blood vessels, the choroid plexus, and the meninges. It has also been demonstrated that TNAP is found in the neuropil of many brain regions, including the olfactory bulb, septum, thalamus and hypothalamus, the cerebral cortex, the inferior and superior colliculi, the tegmentum, and the dorsal and ventral medulla [64]. Studies have shown that the hydrolysis of ATP to adenosine in neuron-glia signaling is inhibited by levamisole, a TNAP inhibitor, but not by ARL67156, an ectoATPase inhibitor in olfactory bulb [70], suggesting that TNAP is physiologically relevant in nucleotide-mediated signaling.

\subsection{Ecto-5'-Nucleotidase}

5'-nucleotidases (E.C. 3.1.3.5) catalyze the hydrolysis of the phosphoric ester bond of 5'-ribonucleotides to the corresponding ribonucleoside and phosphate. 5'-nucleotidases have been found in bacteria, vertebrate tissues and plants cells and they exhibit large dissimilarities in the substrates hydrolyzed, as well as, in substrate specificity [71,72]. Seven human 5'-nucleotidases have been isolated and characterized, and five of the enzymes have been found to be localized to the cytosol, one to the mitochondrial matrix and one to the outer plasma membrane [73]. On the basis of primary sequence homology, ecto-5'-NT was found to be an orthologue of bacterial 5'-nucleotidases and to belong to a superfamily of metallophosphoesterases characterized by a dinuclear metal center [74]. The mammalian ecto-5'-nucleotidase consists of two (glyco) protein subunits, which are tethered by non-covalent bonds [75], bind zinc and other divalent metal ions at the N-terminal domain [72] and is anchored to the plasma membrane at the C-terminus by a glycosylphosphatidylinositol molecule [71]. Like other surface-located enzymes, ecto-5' -nucleotidase, also known as CD73, has been implicated in non-enzymatic functions such as T-cell activation and cell-cell adhesion [76].

The central function of ecto-5'-nucleotidase is the extracellular production of nucleoside [77]. This enzyme, together with other ectonucleotidases, terminates the activity of signaling nucleotides that act on $\mathrm{P} 2 \mathrm{X}$ and $\mathrm{P} 2 \mathrm{Y}$ receptors. Ecto-5' -nucleotidase is present in basically all tissues and its 
primary structure has been determined from enzymes isolated from bovine and rat liver, electric ray brain, mouse kidney and human placenta. These experiments have shown that the enzyme consists of 548 amino acids with a molecular mass varying between 62 and $74 \mathrm{kDa}$. [71,78]. The protein exists as a homodimer with interchain disulfide bridges [71]. However, recent data have shown that the ecto-5'nucleotidase subunits in dimmers are not linked by disulfide bridges, but by non-covalent bonds [79]. The enzyme hydrolyzes a variety of nucleoside 5'-nucleoside monophosphates such as AMP, CMP, UMP, IMP and GMP, but shows no activity towards nucleoside 2'- and 3'-monophosphates. Normally AMP is the most successfully hydrolyzed nucleotide and the $\mathrm{K}_{\mathrm{M}}$ values are in the low micromolar range (3$50 \mu \mathrm{M})$. ADP and ATP are competitive inhibitors, with inhibition constants also in the low micromolar range [71]. Like other GPI-anchored proteins, the enzyme ecto-5'nucleotidase/CD73 is mainly localized in these microdomains, remains relatively resistant to solubilization by nonionic detergents and can be cleaved from the cell membrane after treatment with phosphatidylinositol-specific phospholipase $\mathrm{C}[76]$.

Ecto-5'-nucleotidase is transiently active within synaptic clefts during development and regeneration. The enzyme is also seen at terminals in the mature retina and olfactory bulb, where spontaneous synaptic turnover occurs at adulthood [80]. Studies have shown that enzyme staining is strongest in the outer plexiform layer and granule cell layer of the olfactory bulb and in the caudoputamen [64]. Other immunopositive brain regions include the synaptic layers of the hippocampus, the cingular cortex with labeled radial fibers, and the molecular layer of the cerebellum. Enhanced enzyme histochemical staining was also observed in mossy fiber terminals of the hippocampus (CA3 region). These results were confirmed in the cd39-knockout mice, as histochemical staining was completely abolished in these animals [64].

All ectonucleotidases and the main features described in this review are illustrated in Fig. (1).

\section{EPILEPSY, SEIZURES, AND ECTONUCLEOTI- DASES}

\subsection{Brain Ectonucleotidases}

There are several studies indicating the involvement of NTPDases, ecto-5'-nucleotidase or APs in the pathophysiology of seizures and epilepsy. Up to date, no report has suggested clearly the possible involvement of E-NPPs in epilepsy. However, since these enzymes are located in CNS (NPP 1-3) and they also retain significant catalytic activity at a physiological $\mathrm{pH}$, they may have an unreported role in epilepsy.

Ecto-ATPase activity is deficient in cultured glia cells raised from neonatal, seizure-prone mice [81]. Nagy et al. [82] showed a significant decrease in ecto-ATPase activity in the posterior part of epileptic hippocampus. Interestingly, the chromosomal position of human CD39/ecto-apyrase ( $10 \mathrm{~g} 23.1$ to q24.1) [83] colocalizes with the gene involved in partial human epilepsy with audiogenic symptoms (10q.22 to 24) [84]. The localization of these genes has led to the hypothesis that CD39 is probably related to epilepsy. Patients with temporal lobe epilepsy have shown an increased distribution of $5^{\prime}$-nucleotidase in the dentate gyrus and in mossy fiber endings in CA4 and CA3 areas, when compared with normal human hippocampus [85].
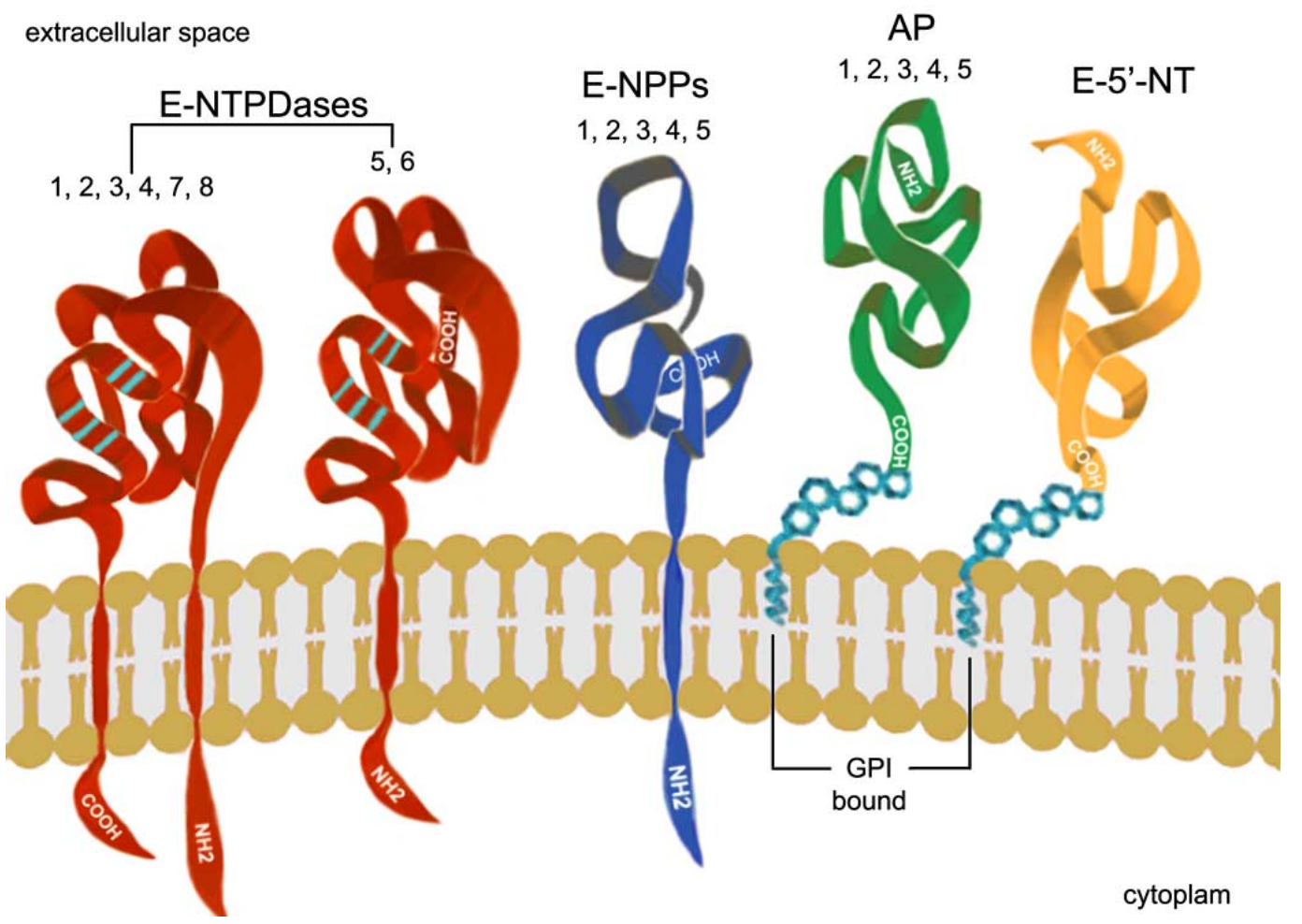

Fig. (1). Extracellular nucleotide-degrading enzymes. Ectonucleotidases present the catalytic site facing the extracellular space. Apyrase conserved regions (ACRs) of NTPDases are represented by blue stripes. NTPDases and NPPs are integral membrane proteins whereas alkaline phosphatases (AP) and ecto-5'-nucleotidase (5'-NT) are glycosylphosphatidylinositol-anchored proteins. 
Several findings have shown that ectonucleotidases are altered in animal models of chronic epilepsy, such as in animals treated with pilocarpine, kainic acid and kindling models. Studies have shown a reduction in ecto-ATPase activity in the rat cerebral cortex during prolonged Status epilepticus (SE) induced by the sequential administration of lithium and pilocarpine [86]. However, ATP diphosphohydrolase and ecto-5'-nucleotidase activities in synaptosomes of the rat hippocampus and cerebral cortex significantly increase at 48 $52 \mathrm{~h}, 7-9$ days and 45-50 days after the induction of SE by pilocarpine or kainic acid models [87]. Only ecto-5'nucleotidase activity remains elevated at 100-110 days after treatment with kainic acid [87]. In addition, increased ecto5 '-nucleotidase staining in the hippocampus during the silent and chronic phases has also been shown [88]. The findings suggest that increased ectonucleotidase activity modulates seizure activity within a time window ( $48 \mathrm{~h}-110$ days) after $\mathrm{SE}$, contributing to the production of extracellular adenosine, a known endogenous neuromodulator [21]. If ATP is released in large amounts, it may promote a dramatic increase in intracellular calcium levels mediated by $\mathrm{P} 2 \mathrm{X}$ receptors, which could cause a significant damage, such as that induced by excess glutamate [89]. If all members of the ectonucleotidase pathway work at an elevated rate, the removal of extracellular ATP and adenosine production would occur at an enhanced rate. Thus, adenosine could modulate the release of a variety of neurotransmitters, including glutamate, acetylcholine, noradrenaline and dopamine [90, 91]. In summary, after SE, an important adaptive plasticity of the ectonucleotidase pathway could occur to decrease levels of ATP, an excitatory neurotransmitter, and increase levels of adenosine, a neuroprotective compound [87].

The activity of 5'-nucleotidase in subcellular cerebellar fractions was also studied after the administration of the convulsant, 3-mercaptopropionic acid. The membrane enzyme presented an increase in its activity in certain fractions containing nerve endings and microsomes in seizure and postseizure periods [92].

In addition, rats showing greater resistance to PTZ kindling present increased ATP hydrolysis in hippocampal and cerebral cortex synaptosomes [93]. To examine whether altered ATP hydrolysis is due to chronic, long-lasting changes induced by kindling or by drug treatment, we investigated enzyme activities after a single acute seizure induced by PTZ. Changes in ectonucleotidase activities were not seen after a single convulsant PTZ injection at any time (immediately, $1 \mathrm{~h}, 24 \mathrm{~h}$, and 5 days) [93]. Studies have shown the presence of 5'-nucleotidase in mossy fibers of the rat dentate gyrus after systemic kainate injection and induction of kindling, with decreased levels present in the normal hippocampus [94]. These alterations seem to be related to chronic, long-lasting synaptic activity induced by kindling, because such changes are not seen in acute seizures, which are probably insufficient to activate these mechanisms. When these results are considered together, they support the hypothesis that changes in nucleotide hydrolysis may represent an important mechanism in the modulation of epileptogenesis [93]. Such changes are represented in Fig. (2).

There is evidence that conventional antiepileptic drugs (AEDs) can influence purinergic transmission in the CNS [95]. It has been shown that carbamazepine can inhibit the in vitro activity of ecto-ATPase in rat brain synaptosomal plasma membranes [96]. However, it has also been shown that carbamazepine treatment cannot change ATP, ADP, and AMP hydrolysis in naive rat brain synaptosomes [97]. Phenytoin and carbamazepine can prevent the increase in ectonucleotidase activity elicited by pilocarpine in brain synaptosomes, but sodium valproate can only inhibit the increase of ATP and ADP hydrolysis in hippocampal synaptosomes. Pilocarpine does not affect gene expression of NTPDase1, NTPDase2, NTPDase3, and ecto-5'-nucleotidase in the cerebral cortex, but increases its levels in the hippocampus. Therefore, anticonvulsant drugs can modulate plastic events related to the increase in nucleotidase expression and activity in pilocarpine-treated rats [97].

Quinolinic acid, an endogenous convulsant compound, overstimulates the glutamatergic system by stimulating $\mathrm{N}$ methyl-D-aspartate receptors, enhancing glutamate release and inhibiting glutamate uptake. Adenine nucleotide hydrolysis in hippocampal slices of adult rats was altered for up to 24 hours after seizure induction by quinolinic acid [98]. Intraperitoneal treatments with $7.5 \mathrm{mg} / \mathrm{kg}$ GMP or guanosine prevented $50 \%$ of seizures by quinolinic acid and increased guanosine cerebrospinal fluid (CSF) levels. Intracerebroventricular treatment with $960 \mathrm{nmol}$ GMP prevented $80 \%$ of seizures and the ecto-5'-nucleotidase inhibitor alpha-betamethyleneadenosine 5'-diphosphate (AOPCP), when injected 3 min before, reduced this anticonvulsant effect to $30 \%$ protection, showing that the effect of GMP as an anticonvulsant may be related to its ability to generate guanosine through the action of ecto-5'-nucleotidase [99].

Studies have suggested that the immature brain is less vulnerable to morphologic and physiologic alterations after SE [100, 101]. Indeed, there is distinct sensitivity in developing rats to pilocarpine when compared to that of adult rats [102]. A previous study demonstrated that 7- to 17-day-old rats subjected to pilocarpine-induced SE do not develop spontaneous recurrent seizures in adulthood [103] and the susceptibility to spontaneous recurrent seizures in the chronic period of the pilocarpine model increases with age [103]. It has been shown that ATP and ADP hydrolysis in the hippocampus and cerebral cortex are not altered by pilocarpine treatment in female and male rats at 7-9, 14-16 and 27-30 days [104]. In addition, there were no changes in AMP hydrolysis in female and male rats subjected to this model at different ages, but a significant increase in AMP hydrolysis (71\%) was observed in cerebral cortex synaptosomes from male rats at 27-30 days [104]. The different sensitivity of developing rats may be related to the immaturity of neuronal networks engaged in the generation and spread of seizure activity and these findings highlight differences between the purinergic system of young and adult rats submitted to the pilocarpine-induced epilepsy.

Studies have demonstrated that mice lacking TNAP have normal skeletal development and, approximately two weeks after birth, develop seizures which are subsequently fatal. Defective metabolism of pyridoxal 5'-phosphate (PLP), characterized by elevated serum PLP levels, results in reduced levels of the inhibitory neurotransmitter GABA in the brain [105]. AP activity was determined in synaptosomes isolated from rat brain and cerebellum after administration of the convulsant 3-mercaptopropionic acid (MP). The enzyme 

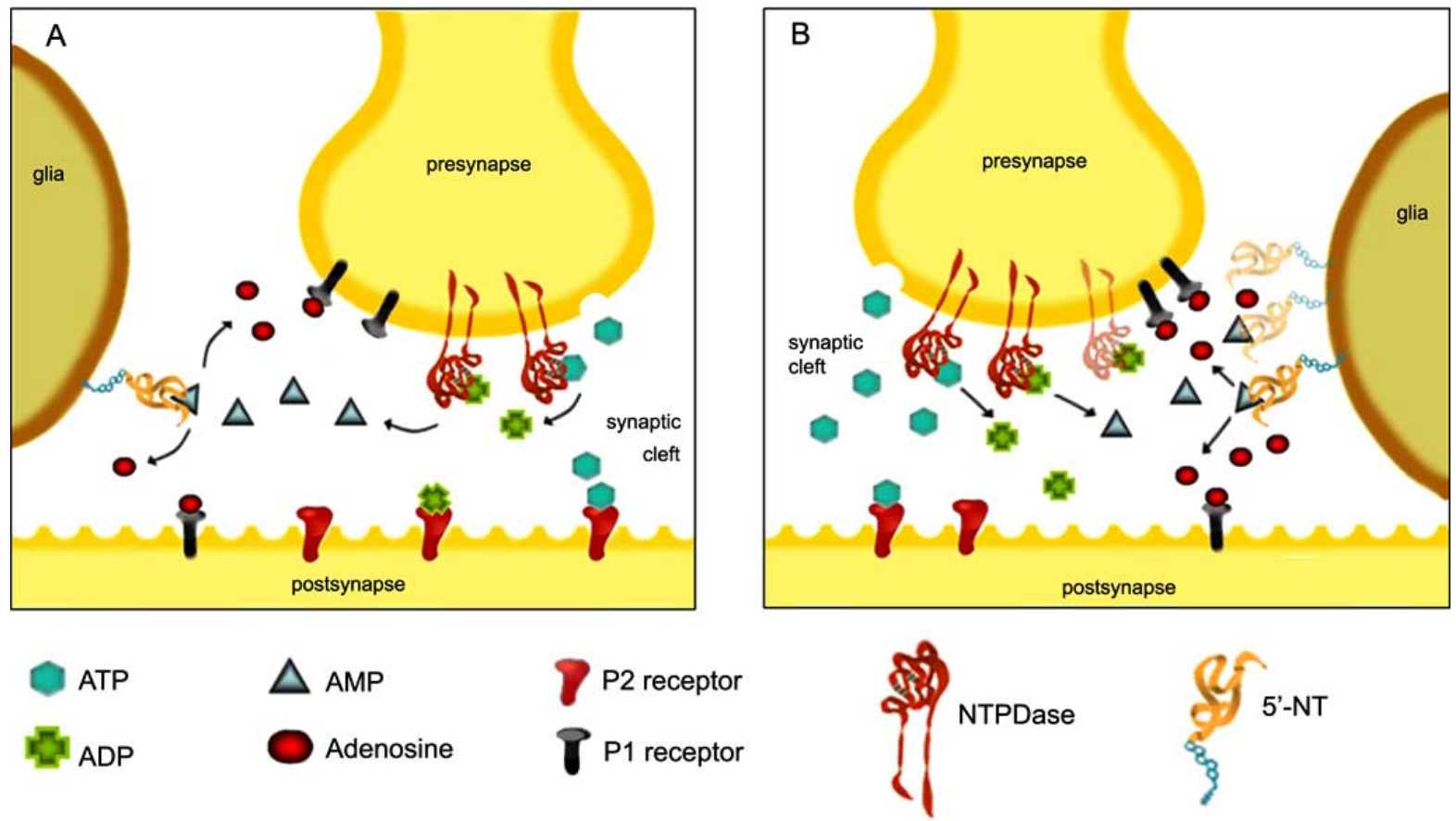

Fig. (2). General profile of ectonucleotidase activities in physiological (A) or in chronic seizures (B) situations. ATP can be released in the synaptic cleft and exert its effects through P2 receptors. ATP signaling is terminated by ectonucleotidases (as NTPDases and 5'nucleotidases) producing adenosine, which can act by P1 receptors (illustrated in A). Most studies have shown that ectonucleotidase activities are increased in chronic seizures or epilepsy, (represented in $\mathbf{B}$ as clearer ectonucleotidases), generating higher adenosine levels in the synaptic cleft when compared to physiological conditions, which activates P1 receptors and may contribute to the modulation of neurotransmitter release.

activity determined in cortical and cerebellar fractions at $\mathrm{pH}$ 9.0 decreased in seizure and postseizure states. Such changes following MP treatment may be related to seizure-induced alterations in phosphate ester levels or protein-kinase activities [106]. However, kindling increases AP activity throughout the brain, elevates aspartate aminotransferase as well as lactate dehydrogenase activity in the frontal cortex and hippocampus and decreases creatine kinase activity in the frontal cortex and cerebellum. Acute seizures of the same intensity do not induce these alterations [107]. The data provide evidence for PTZ-kindling related enzyme changes which are distinct from PTZ-seizure induced changes.

\subsection{Soluble Nucleotidases}

Although it is well established that the breakdown of ATP is mediated by membrane-bound ectonucleotidases, studies have indicated that soluble nucleotidases, probably released from sympathetic nerves, are also involved in ATP breakdown to adenosine [3,4]. Studies have shown that a single convulsive PTZ injection increases ATP, ADP and AMP hydrolysis in rat blood serum (40-50\%) for up to $24 \mathrm{~h}$ [108]. Likewise, animals subjected to PTZ-kindling (30 $\mathrm{mg} / \mathrm{kg}$ PTZ, i.p., once every $48 \mathrm{~h}$, totaling 10 stimulations) exhibit increased ATP, ADP, and AMP hydrolysis (42, 40, and $45 \%$, respectively), while phosphodiesterase activity remains unchanged [109]. These results suggest once more that enhanced ectonucleotidase activity and, possibly, increases in adenosine levels, could represent an important compensatory mechanism in the development of chronic epilepsy. The fact that this increase can also be measured in serum suggests that these enzymes may be useful as plasma markers of seizures in epilepsy [109]. Increased soluble nu- cleotidase activity in cerebrospinal fluid is observed $10 \mathrm{~min}$ after pentylenetetrazol-induced seizure and these values return to control levels after $240 \mathrm{~min}$, whereas guanosine and inosine levels increase only after $30 \mathrm{~min}$. Taken together, these results suggest that such events may modulate seizure expression, but are nevertheless promising biochemical brain markers to evaluate neural injury after acute seizures [110]. Pentylenetetrazol kindling also has been shown to alter adenine and guanine nucleotide catabolism in rat hippocampal slices and in cerebrospinal fluid [111]. A significant decrease $(50 \%)$ in the expression of NTPDase1 was observed, but there were no changes in NTPDase2, 3, 5, 6 and $5^{\prime}$ nucleotidase transcript levels in the hippocampus of PTZkindled rats. Such alterations indicate that the modulatory role of purines in the CNS could be affected by PTZkindling [111].

Recently, serum ATP, ADP, and AMP hydrolysis rates and soluble nucleotide phosphodiesterase (PDEase) activity at $5,10,15,30$ and $60 \mathrm{~min}$, and $12 \mathrm{~h}$ were evaluated following an epileptic event in fifteen patients [112]. In comparison with controls, ATP, ADP and AMP hydrolysis rates were significantly increased at $5 \mathrm{~min}$ and up to $30 \mathrm{~min}$ following the epileptic event. In contrast to ADP and AMP, ATP hydrolysis remained significantly increased at $60 \mathrm{~min}$, and returned to basal levels after $12 \mathrm{~h}$. Serum PDEase activity was also significantly higher in patients than in healthy subjects, and peaked at $15 \mathrm{~min}$ and remained increased up to $60 \mathrm{~min}$ following the epileptic episode. The authors hypothesized that this higher nucleotidase activity might play a role in the modulation of epileptic events [112]. 
A previous study reported time-dependent changes in adenine nucleotide hydrolysis induced by electroconvulsive shock (ECS), a validated animal model of an effective antidepressive treatment [113]. The results with the acute model showed an abrupt inhibition of hydrolysis immediately after a single ECS with recuperation to basal levels shortly thereafter. However, stimulation in the chronic model led to a more persistent increase in the hydrolysis of nucleotides (until the 7 th post-treatment day). These results support the idea that adenine nucleotides may be involved in the biochemical mechanisms underlying longer lasting therapeutic effects associated with electroconvulsive therapy, and suggest that peripheral markers may contribute to the evaluation of activity in the CNS.

The co-existence of several enzymes in the central nervous system represents a sophisticated route for the appearance and inactivation of extracellular agonists on the cell surface. Therefore, the regulation of the nucleotidase pathway and, consequently in the nucleotide levels, may play a modulatory role during the evolution of behavioral and pathophysiological changes related to temporal lobe epilepsy and may represent an mechanism involved in epileptogenesis. Clearly, identifying changes induced by seizures and epilepsy and the exact mechanisms by which these enzymes regulate local nucleotide and nucleoside concentrations will be an area of intense interest in the future and may open up further research to assess the potential therapeutic and diagnostic applications for ectonucleotidases.

\section{ACKNOWLEDGEMENTS}

This work is dedicated to our great mentor and friend, Professor João José Freitas Sarkis, in homage to his contributions to the study of ectonucleotidases. The authors thank Coordenação de Aperfeiçoamento de Pessoal de Nível Superior (CAPES), Conselho Nacional de Desenvolvimento Científico e Tecnológico (CNPq), Fundação de Amparo à Pesquisa do Estado do Rio Grande do Sul (FAPERGS) and by the FINEP research grant "Rede Instituto Brasileiro de Neurociência (IBN-Net)" \# 01.06.0842-00.

\section{REFERENCES}

[1] Ralevic V, Burnstock G. Receptors for purines and pyrimidines. Pharmacol Rev 1998; 50: 413-92.

[2] Lazarowski ER, Boucher RC, Harden TK. Mechanisms of release of nucleotides and integration of their action as P2X- and P2Yreceptor activating molecules. Mol Pharmacol 2003; 64(4): 785-95.

[3] Yegutkin GG, Henttinen T, Jalkanen S. Extracellular ATP formation on vascular endothelial cells is mediated by ecto-nucleotide kinase activities via phosphotransfer reactions. FASEB J 2001; 15(1): 251-60.

[4] Todorov LD, Mihaylova-Todorova S, Westfall TD, et al. Evaluation of a method for controlling molecular scaffold diversity in de novo ligand design. J Comput Aid Mol Des 1997; 11: 175-92.

[5] Anderson CM, Parkinson FE. Potential signalling roles for UTP and UDP: sources, regulation and release of uracil nucleotides. Trends Pharmacol Sci 1997; 18(10): 387-92.

[6] Abbracchio MP, Burnstock G, Boeynaems JM, et al. International Union of Pharmacology LVIII: update on the P2Y G proteincoupled nucleotide receptors: from molecular mechanisms and pathophysiology to therapy. Pharmacol Rev 2006; 58(3): 281-41.

[7] Fields RD, Burnstock G. Purinergic signalling in neuron-glia interactions. Nat Rev Neurosci 2006; 7(6): 423-36.

[8] Khakh BS, Burnstock G, Kennedy C, et al. International union of pharmacology. XXIV. Current status of the nomenclature and properties of P2X receptors and their subunits. Pharmacol Rev 2001; 53(1): 107-18.
Agresti C, Meomartini ME, Amadio S, et al. Metabotropic P2 receptor activation regulates oligodendrocyte progenitor migration and development. Glia 2005; 50(2): 132-44.

[10] Zimmermann H. Ectonucleotidases: some developments and a note on nomenclature. Drug Dev Res 2001; 52: 44-56.

[11] Yegutkin GG. Nucleotide- and nucleoside-converting ectoenzymes: Important modulators of purinergic signalling cascade. Biochim Biophys Acta 2008; 1783(5): 673-94.

[12] Robson S, Sévigny J, Zimmermann, H. The E-NTPDase family of ectonucleotidases: structure function relationships and pathophysiological significance. Purinergic Signal 2006; 2: 409-30.

[13] Schetinger MR, Morsch VM, Bonan CD, et al. NTPDase and 5'nucleotidase activities in physiological and disease conditions: new perspectives for human health. Biofactors 2007; 31(2): 77-98

[14] Enjyoji K, Sévigny J, Lin Y, et al. Targeted disruption of cd39/ATP diphosphohydrolase results in disordered hemostasis and thromboregulation. Nat Med 1999; 5(9): 1010-7.

[15] Bonan CD, Schetinger MRC, Battastini AMO, Sarkis JJF. Ectonucleotidases and synaptic plasticity: implications in physiological and pathological conditions. Drug Dev Res 2001; 52: 57-65.

[16] Cunha RA. Regulation of the ecto-nucleotidase pathway in rat hippocampal nerve terminals. Neurochem Res 2001; 26: 979-91.

[17] Kong W, Engel K, Wang J. Mammalian nucleoside transporters. Curr Drug Metab 2004; 5(1): 63-84.

[18] Ribeiro JA, Sebastião AM, de Mendonça A. Adenosine receptors in the nervous system: pathophysiological implications. Prog Neurobiol 2002; 68(6): 377-92.

[19] Kirkpatrick KA, Richardson PJ. Adenosine receptor-mediated modulation of acetylcholine release from rat striatal synaptosomes. Br J Pharmacol 1993; 110(3): 949-54.

[20] During MJ, Spencer DD. Adenosine: a potential mediator of seizure arrest and postictal refractoriness. Ann Neurol 1992; 32(5): 618-24.

[21] Berman RF, Fredholm BB, Aden U, O'Connor WT. Evidence for increased dorsal hippocampal adenosine release and metabolism during pharmacologically induced seizures in rats. Brain Res 2000; 872(1-2): 44-53.

[22] Boison D. Adenosine and epilepsy: from therapeutic rationale to new therapeutic strategies. Neuroscientist 2005; 11(1): 25-36.

[23] Pagonopoulou O, Efthimiadou A, Asimakopoulos B, Nikolettos NK. Modulatory role of adenosine and its receptors in epilepsy: possible therapeutic approaches. Neurosci Res 2006; 56(1): 14-20.

[24] Plesner L. Ecto-ATPases: Identities and Functions. Int Rev Cytol 1995; 158: 141-14.

[25] Zimmermann H.Extracellular purine metabolism. Drug Dev Res 1996; 39: 337-52.

[26] Gendron FP, Benrezzak O, Krugh BW, Kong K, Weisman GA, Beaudoin AR. Purine signaling and potential new therapeutic approach: Possible outcome of NTPDase inhibition. Curr Drug Targets 2002; 3: 229-45.

[27] Gendron FP, Halbfinger E, Fischer B, Duval M, D'-Orléans-Juste $\mathrm{P}$, Beaudoin AR. Novel inhibitors of nucleoside triphosphate diphosphohydrolases: Chemical synthesis and biochemical and pharmacological characterization. J Med Chem 2000; 43: 2239-47.

[28] Handa M, Guidotti G. Purification and cloning of a soluble ATPdiphosphohydrolase (apyrase) from potato tubers (solanum tuberosum). Biochem Biophys Res Commun 1996; 218: 916-23.

[29] Kegel B, Braun N, Heine CR, Maliszewski CR, Zimmermann H An ecto-ATPase and Ecto-ATP diphosphodydrolase are expressed in rat brain Neuropharmacol 1997; 36: 1189-1200.

[30] Ivanenkov VV, Sévigny J, Kirley TL. Trafficking and intracellular ATPase activity of human ecto-nucleotidase NTPDase 3 and the effect of ER-targeted NTPDase3 on protein folding. Biochemistry 2008; 47(35): 9184-97.

[31] Kukulski F, Lévesque SA, Lavoie ÉG, et al. Comparative hydrolysis of P2 receptor agonists by NTPDase 1,2, 3 and 8 . Purinergic Signal 2005; 1: 193-204.

[32] Wang TF, Ou Y, Guidotti G. The transmembrane domains of ectoapyrase (CD39) affect its enzymatic activity and quaternary structure. J Biol Chem 1998; 273: 24814-24821.

[33] Ivanenkov VV, Meller J, Kirley TL. Characterization of disulfide bonds in human nucleoside triphosphate diphosphohydrolase 3 (NTPDase3): Implications for NTPDase structural modeling. Biochemistry 2005; 44: 8998-9012.

[34] Musi E, Islam N, Drosopoulos HF. Constraints imposed by transmembrane domains affect enzymatic activity of membrane- 
associated human CD 39/NTPDase1 mutants. Arch Biochem Biophys 2007; 46: 30-9.

[35] Zebisch M, Sträter N. Structural insight into signal conversion and inactivation by NTPDase 2 in purinergic signaling. Proc Natl Acad Sci USA 2008; 105(19): 6882-7.

[36] Zimmermann H, Braun N, Kegel B, Heine P. New insights into molecular structure and function of ectonucleotidases in the nervous system. Neurochem Int 1998; 32(5-6): 421-5.

[37] Braun N, Sévigny J, Robson SC, et al. Assignment of ectonucleoside triphosphate diphosphohydrolase-1/cd39 expression to microglia and vasculature of the brain. Eur J Neurosci 2000; 12(12): 4357-66.

[38] Braun N, Sévigny J, Mishra SK, et al. Expression of the ectoATPase NTPDase2 in the germinal zones of the developing and adult rat brain. Eur J Neurosci 2003; 17(7): 1355-64.

[39] Shukla V, Zimmermann H, Wang L, et al. Functional expression of the ecto-ATPase NTPDase2 and of nucleotide receptors by neuronal progenitor cells in the adult murine hippocampus. J Neurosci Res 2005; 80(5): 600-10.

[40] Wink MR, Braganhol E, Tamajusuku AS, et al. Nucleoside triphosphate diphosphohydrolase-2 (NTPDase2/CD39L1) is the dominant ectonucleotidase expressed by rat astrocytes. Neuroscience 2006; 138(2): 421-32.

[41] Lavoie EG, Kukulski F, Lévesque SA, Lecka J, Sévigny J. Cloning and characterization of mouse nucleoside triphosphate diphosphohydrolase-3. Biochem Pharmacol 2004; 67(10): 1917-26.

[42] Vorhoff T, Zimmermann H, Pelletier J, Sévigny J, Braun N. Cloning and characterization of the ecto-nucleotidase NTPDase 3 from rat brain: Predicted secondary structure and relation to members of the NTPDase family and actin. Purinergic Signal 2005; 1: 259-70.

[43] Belcher SM, Zsarnovszky A, Crawford PA, Hemani H, Spurling L, Kirley TL. Immunolocalization of ecto-nucleoside triphosphate diphosphohydrolase 3 in rat brain: implications for modulation of multiple homeostatic systems including feeding and sleep-wake behaviors. Neuroscience 2006; 137(4): 1331-46.

[44] Biederbick A, Kosan C, Kunz J, Elsässer HP. First apyrase splice variants have different enzymatic properties. J Biol Chem 2000; 275(25): 19018-24.

[45] Páez JG, Recio JA, Rouzaut A, Notario V. Identity between the PCPH proto-oncogene and the CD39L4 (ENTPD5) ectonucleoside triphosphate diphosphohydrolase gene. Int J Oncol 2001; 19(6): 1249-54.

[46] Hicks-Berger CA, Chadwick BP, Frischauf AM, Kirley TL. Expression and characterization of soluble and membrane-bound human nucleoside triphosphate diphosphohydrolase 6 (CD39L2). J Biol Chem 2000; 275(44): 34041-5

[47] Shi JD, Kukar T, Wang CY, et al. Molecular cloning and characterization of a novel mammalian endo-apyrase (LALP1). J Biol Chem 2001; 276(20): 17474-8.

[48] Bigonnesse F, Lévesque SA, Kukulski F, et al. Cloning and characterization of mouse nucleoside triphosphate diphosphohydrolase-8. Biochemistry 2004; 43(18): 5511-9.

[49] Gijsbers R, Ceulemans H, Stalmans W, Bollen M. Structural and catalytic similarities between nucleotide pyrophosphatases/phosphodiesterases and alkaline phosphatases. J Biol Chem 2001; 276(2): 1361-8.

[50] Goding JW, Grobben B, Slegers H. Physiological and pathophysiological functions of the ecto-nucleotide pyrophosphatase/phosphodiesterase family. Biochim Biophys Acta 2003; 1638(1): 1-19.

[51] Cimpean A, Stefan C, Gijsbers R, Stalmans W, Bollen M. Substrate-specifying determinants of the nucleotide pyrophosphatases/phosphodiesterases NPP1 and NPP2. Biochem J 2004; 381(Pt 1): 71-7.

[52] McLennan AG. Dinucleoside polyphosphates-friend or foe? Pharmacol Ther 2000; 87(2-3): 73-89.

[53] Asensio AC, Rodríguez-Ferrer CR, Oaknin S, Rotllán P. Biochemical and immunochemical characterisation of human diadenosine triphosphatase provides evidence for its identification with the tumour suppressor Fhit protein. Biochimie 2006; 88(5): 461-71.

[54] Gijsbers R, Aoki J, Arai H, Bollen M. The hydrolysis of lysophospholipids and nucleotides by autotaxin (NPP2) involves a single catalytic site. FEBS Lett 2003; 538(1-3): 60-4.

[55] Sakagami H, Aoki J, Natori Y, et al. Biochemical and molecular characterization of a novel choline-specific glycerophosphodiester phosphodiesterase belonging to the nucleotide pyrophospha- tase/phosphodiesterase family. J Biol Chem 2005; 280(24): 2308493.

[56] Asensio AC, Rodríguez-Ferrer CR, Castañeyra-Perdomo A, Oaknin S, Rotllán P. Biochemical analysis of ecto-nucleotide pyrophosphatase phosphodiesterase activity in brain membranes indicates involvement of NPP1 isoenzyme in extracellular hydrolysis of diadenosine polyphosphates in central nervous system. Neurochem Int 2007; 50(4): 581-90.

[57] Harahap AR, Goding JW. Distribution of the murine plasma cell antigen PC-1 in non-lymphoid tissues. J Immunol 1988; 141(7): 2317-20.

[58] Grobben B, Anciaux K, Roymans D, et al. An ecto-nucleotide pyrophosphatase is one of the main enzymes involved in the extracellular metabolism of ATP in rat C6 glioma. J Neurochem 72(2): 826-34

[59] Claes P, Van Kolen K, Roymans D, et al. Reactive blue 2 inhibition of cyclic AMP-dependent differentiation of rat C6 glioma cells by purinergic receptor-independent inactivation of phosphatidylinositol 3-kinase. Biochem Pharmacol 2004; 67(8): 1489-98.

[60] Fuss B, Baba H, Phan T, Tuohy VK, Macklin WB. Phosphodiesterase I, a novel adhesion molecule and/or cytokine involved in oligodendrocyte function. J. Neurosci 1997; 17: 9095-103.

[61] Xiang Z, Burnstock G. Changes in expression of P2X purinoceptors in rat cerebellum during postnatal development. Brain Res Dev Brain Res 2005; 156(2): 147-57.

[62] Blass-Kampmann S, Kindler-Röhrborn A, Deissler H, D'Urso D, Rajewsky MF. In vitro differentiation of neural progenitor cells from prenatal rat brain: common cell surface glycoprotein on three glial cell subsets. J Neurosci Res 1997; 48(2): 95-111.

[63] Cognato G de P, Czepielewski RS, Sarkis JJ, Bogo MR, Bonan CD. Expression mapping of ectonucleotide pyrophosphatase/phosphodiesterase 1-3 (E-NPP1-3) in different brain structures during rat development. Int J Dev Neurosci 2008; 26(6): 593-8.

[64] Langer D, Hammer K, Koszalka P, et al. Distribution of ectonucleotidases in the rodent brain revisited. Cell Tissue Res 2008; 334(2): 199-217.

[65] Millán JL. Alkaline Phosphates: Structure, substrate specificity and functional relatedness to other members of a large superfamily of enzymes. Purinergic Signal 2006; 2(2): 335-41.

[66] Narisawa S, Hoylaerts MF, Doctor KS, Fukuda MN, Alpers DH, Millán JL. A novel phosphatase upregulated in Akp3 knockout mice. Am J Physiol Gastrointest Liver Physiol 2007; 293(5): G1068-77.

[67] Fonta C, Négyessy L, Renaud L, Barone P. Areal and subcellular localization of the ubiquitous alkaline phosphatase in the primate cerebral cortex: evidence for a role in neurotransmission. Cereb Cortex 2004; 14(6): 595-609.

[68] Vorbrodt AW, Lossinsky AS, Wisniewski HM. Localization of alkaline phosphatase activity in endothelia of developing and mature mouse blood-brain barrier. Dev Neurosci 1986; 8(1): 1-13.

[69] Chilingaryan A, Chilingaryan AM, Martin GG. The threedimensional detection of microvasculatory bed in the brain of white rat Rattus norvegicus by a $\mathrm{Ca}^{2+}$-ATPase method. Brain Res 2006; 1070(1): 131-8.

[70] Doengi M, Deitmer JW, Lohr C. New evidence for purinergic signaling in the olfactory bulb: A2A and P2Y1 receptors mediate intracellular calcium release in astrocytes. FASEB J 2008; 22(7): 2368-78.

[71] Zimmermann H. 5'-Nucleotidase: molecular structure and functional aspects. Biochem J 1992; 285: 345-365.

[72] Sträter N. Ecto-5'-nucleotidase: Structure function relationships. Purinergic Signal 2006; 2(2): 343-50.

[73] Hunsucker SA, Mitchell BS, Spychala J. The 5'-nucleotidases as regulators of nucleotide and drug metabolism. Pharmacol Ther 2005; 107(1): 1-30.

[74] Koonin EV. Conserved sequence pattern in a wide variety of phosphoesterases. Protein Sci 1994; 3(2): 356-8

[75] Martínez-Martínez A, Muñoz-Delgado E, Campoy FJ, et al. The ecto-5'-nucleotidase subunits in dimers are not linked by disulfide bridges but by non-covalent bonds. Biochim Biophys Acta 2000; 1478(2): 300-8.

[76] Resta R, Yamashita Y, Thompson LF.Ecto-enzyme and signaling functions of lymphocyte CD73. Immunol Rev 1998; 161: 95-109.

[77] Colgan SP, Eltzschig HK, Eckle T, Thompson LF. Physiological roles for ecto-5'-nucleotidase (CD73). Purinergic Signal 2006; 2(2): 351-60. 
[78] Resta R, Hooker SW, Hansen KR, et al. Murine ecto-5'nucleotidase (CD73): cDNA cloning and tissue distribution. Gene 1993; 133(2): 171-7.

[79] Martínez-Martínez A, Muñoz-Delgado E, Campoy FJ, et al. The ecto-5'-nucleotidase subunits in dimers are not linked by disulfide bridges but by non-covalent bonds. Biochim Biophys Acta 2000; 1478: 300-8.

[80] Schoen SW, Kreutzberg GW. 5'-nucleotidase enzyme cytochemistry as a tool for revealing activated glial cells and malleable synapses in CNS development and regeneration. Brain Res Brain Res Protoc 1997; 1(1): 33-43.

[81] Trams EG, Lauter CJ. Ecto-ATPase deficiency in glia of seizureprone mice. Nature 1978; 271(5642): 270-1.

[82] Nagy AK, Houser CR, Delgado-Escueta AV. Synaptosomal ATPase activities in temporal cortex and hippocampal formation of humans with focal epilepsy. Brain Res 1990; 529(1-2): 192-201.

[83] Maliszewski CR, Delespesse GJ, Schoenborn MA, et al. The CD39 lymphoid cell activation antigen: molecular cloning and structural characterization. J Immunol 1994; 153(8): 3574-83.

[84] Ottman R, Risch N, Hauser WA, et al. Localization of a gene for partial epilepsy to chromosome 10q. Nat Genet 1995; 10(1): 56-60.

[85] Lie AA, Blumcke I, Beck H, Wiestler OD, Elger CE, Schoen SW. 5 '-Nucleotidase activity indicates sites of synaptic plasticity and reactive synaptogenesis in the human brain. J Neuropathol Exp Neurol 1999; 58(5): 451-8.

[86] Nagy AK, Walton NY, Treiman DM. Reduced cortical ectoATPase activity in rat brains during prolonged status epilepticus induced by sequential administration of lithium and pilocarpine. Mol Chem Neuropathol 1997; 31(2): 135-47.

[87] Bonan CD, Walz R, Pereira GS, et al. Changes in synaptosomal ectonucleotidase activities in two rat models of temporal lobe epilepsy. Epilepsy Res 2000; 39(3): 229-38.

[88] Vianna EP, Ferreira AT, Dona F, Cavalheiro EA, da Silva Fernandes MJ. Modulation of seizures and synaptic plasticity by adenosinergic receptors in an experimental model of temporal lobe epilepsy induced by pilocarpine in rats. Epilepsia 2005; 46(Suppl 5): 166-73.

[89] Edwards FA, Gibb AJ, Colquhoun D. ATP receptor-mediated synaptic currents in the central nervous system. Nature 1992; 359(6391): 144-7.

[90] Di Iorio P, Ballerini P, Caciagli F, Ciccarelli R. Purinoceptormediated modulation of purine and neurotransmitter release from nervous tissue. Pharmacol Res 1998; 37(3): 169-78.

[91] Burnstock G. Physiology and pathophysiology of purinergic neurotransmission. Physiol Rev 2007; 87(2): 659-797.

[92] Girardi E, Perez Raffo G, Rodriguez de Lores Arnaiz G. A study of 5 '-nucleotidase activity in subcellular fractions of rat cerebellum after the administration of the convulsant 3-mercaptopropionic acid. Mol Chem Neuropathol 1989; 11(2): 65-75.

[93] Bonan CD, Amaral OB, Rockenbach IC, et al. Altered ATP hydrolysis induced by pentylenetetrazol kindling in rat brain synaptosomes. Neurochem Res 2000b; 25(6): 775-9.

[94] Schoen SW, Ebert U, Loscher W. 5'-Nucleotidase activity of mossy fibers in the dentate gyrus of normal and epileptic rats. Neuroscience 1999; 93(2): 519-26.

[95] Borowicz KK, Luszczki J, Czuczwar SJ. 2-Chloroadenosine, a preferential agonist of adenosine A1 receptors, enhances the anticonvulsant activity of carbamazepine and clonazepam in mice. Eur Neuropsychopharmacol 2002; 12(2): 173-9.
[96] Horvat A, Orlic T, Banjac A, Momic T, Petrovic S, Demajo M. Inhibition of rat brain ecto-atpase activity by various drugs. Gen Physiol Biophys 2006; 25(1): 91-105.

[97] Cognato GP, Bruno AN, da Silva RS, Bogo MR, Sarkis JJ, Bonan $\mathrm{CD}$. Antiepileptic drugs prevent changes induced by pilocarpine model of epilepsy in brain ecto-nucleotidases. Neurochem Res 2007; 32(6): 1046-55.

[98] Nicolaidis R, Bruno AN, Sarkis JJ, Souza DO. Increase of adenine nucleotide hydrolysis in rat hippocampal slices after seizures induced by quinolinic acid. Neurochem Res 2005; 30(3): 385-90.

[99] Soares FA, Schmidt AP, Farina M et al.Anticonvulsant effect of GMP depends on its conversion to guanosine. Brain Res 2004; 1005(1-2): 182-6.

[100] Stafstrom CE, Chronopoulos A, Thurber S, Thompson JL, Holmes GL. Age-dependent cognitive and behavioral deficits after kainic acid seizures. Epilepsia 1993; 34(3): 420-32.

[101] Haut SR, Velísková J, Moshé SL. Susceptibility of immature and adult brains to seizure effects. Lancet Neurol 2004; 3(10): 608-17.

[102] Cavalheiro EA, Silva DF, Turski WA, Calderazzo-Filho LS, Bortolotto ZA, Turski L. The susceptibility of rats to pilocarpineinduced seizures is age-dependent. Brain Res 1987; 465(1-2): 4358

[103] Priel MR, dos Santos NF, Cavalheiro EA. Developmental aspects of the pilocarpine model of epilepsy. Epilepsy Res 1996; 26(1): $115-21$.

[104] Cognato GP, Bruno AN, Vuaden FC, Sarkis JJ, Bonan CD. Ontogeneic profile of ectonucleotidase activities from brain synaptosomes of pilocarpine-treated rats. Int J Dev Neurosci 2005; 23(8): 703-9.

[105] Waymire KG, Mahuren JD, Jaje JM, Guilarte TR, Coburn SP, MacGregor GR. Mice lacking tissue non-specific alkaline phosphatase die from seizures due to defective metabolism of vitamin B-6. Nat Genet 1995; 11(1): 45-51

[106] Rodriguez de Lores Arnaiz G, Girardi E, Pérez Raffo G. Differential changes in CNS phosphatase activities during seizures. Neuroreport 1993; 4(1): 100-2.

[107] Eraković V, Zupan G, Varljen J, Laginja J, Simonić A. Altered activities of rat brain metabolic enzymes caused by pentylenetetrazol kindling and pentylenetetrazol--induced seizures. Epilepsy Res 2001; 43(2): 165-73.

[108] Bruno AN, Oses JP, Bonan CD, Walz R, Battastini AM, Sarkis JJ. Increase of nucleotidase activities in rat blood serum after a single convulsive injection of pentylenetetrazol. Neurosci Res 2002; 43(3): $283-8$

[109] Bruno AN, Oses JP, Amaral O, et al. Changes in nucleotide hydrolysis in rat blood serum induced by pentylenetetrazol-kindling. Brain Res Mol Brain Res 2003; 114(2): 140-5.

[110] Oses JP, Cardoso CM, Germano RA, et al. Soluble NTPDase: An additional system of nucleotide hydrolysis in rat blood serum. Life Sci 2004; 74(26): 3275-84

[111] Oses JP, Viola GG, de Paula Cognato G, et al Pentylenetetrazol kindling alters adenine and guanine nucleotide catabolism in rat hippocampal slices and cerebrospinal fluid. Epilepsy Res 2007; 75(2-3): 104-11.

[112] Grosso S, Rocchi R, Margollicci M, et al. Postictal serum nucleotidases activities in patients with epilepsy. Epilepsy Res 2009; 84(1): 15-20.

[113] Busnello JV, Oses JP, da Silva RS, et al. Peripheral nucleotide hydrolysis in rats submitted to a model of electroconvulsive therapy. Prog Neuropsychopharmacol Biol Psychiatry 2008; 32(8): $1829-33$ 